\title{
Wollastonite/forsterite composite scaffolds offer better surface for hydroxyapatite formation
}

\author{
R LAKSHMI $^{1}$, RAJAN CHOUDHARY ${ }^{2}$, DEEPALEKSHMI PONNAMMA ${ }^{3}$, \\ KISHOR KUMAR SADASIVUNI ${ }^{4}$ and SASIKUMAR SWAMIAPPAN ${ }^{5}, * \mathbb{D}$ \\ ${ }^{1}$ Department of Chemistry, Auxilium College, Vellore, Tamil Nadu 632006, India \\ ${ }^{2}$ Division of Chemistry, Department of Science and Humanities, Saveetha School of Engineering, Saveetha Institute of \\ Medical and Technical Sciences (SIMATS), Chennai, Tamil Nadu 602105, India \\ ${ }^{3}$ Center for Advanced Materials, Qatar University, P.O. Box 2713, Doha, Qatar \\ ${ }^{4}$ Department of Mechanical and Industrial Engineering, Qatar University, P.O. Box 2713, Doha, Qatar \\ ${ }^{5}$ Department of Chemistry, School of Advanced Sciences, Vellore Institute of Technology, Vellore, Tamil Nadu 632014, \\ India \\ *Author for correspondence (ssasikumar@vit.ac.in)
}

MS received 16 August 2018; accepted 27 November 2018; published online 4 April 2019

\begin{abstract}
The present work deals with a comparative study of ceramic/ceramic composites for the development of scaffolds for biomedical applications. Wollastonite and forsterite were synthesized by a sol-gel combustion method. The influence of constituents and composition on apatite deposition was studied by fabricating wollastonite/forsterite composites. The X-ray diffraction pattern explains the bone like-apatite deposition within early stages of immersion. The atomic force microscopy micrographs revealed that with an increase in wollastonite content in the composites the roughness was enhanced. Dissolution studies further confirmed the rapid consumption of $\mathrm{Ca}$ and $\mathrm{P}$ ions from the simulated body fluid. Hence, apatite formation was observed to be more on the surface of a composite containing a higher amount of wollastonite. The results suggest that composites have more influence on the biomineralization activity when compared with pure bioceramics.
\end{abstract}

Keywords. Wollastonite; forsterite; composites; roughness; simulated body fluid; apatite.

\section{Introduction}

The major requirements for a typical biomaterial are biodegradability, enough strength and excellent efficiency to interact with the surrounding tissues and bones in the body. These criteria can be achieved by developing bioactive porous ceramic-ceramic scaffolds which can trigger the regeneration of new bone tissues and the biomechanical load tolerance during bone formation [1-4]. Forsterite $\left(\mathrm{Mg}_{2} \mathrm{SiO}_{4}\right)$ is a bioceramic having mechanical properties superior to hydroxyapatite (HAp) and bioglass [5]. The role of divalent cations like $\mathrm{Mg}^{2+}$ in bone remodelling, skeletal development, human metabolism and cellular processes is well established. The in-vitro studies of forsterite reveal poor apatite deposition ability and an extremely slow degradation rate [6]. Moreover, the apatite formation on the surface of forsterite can be induced by fabricating its composites [7]. It is reported that nanocrystalline forsterite can enhance the fracture toughness of the bioactive glass matrix without deteriorating its biomineralization properties [8]. The HAp-forsterite-bioactive glass nanocomposite on a 316 litres stainless steel shows an increase in the HAp formation with an increase in the forsterite amount in the composite [9]. Recently, a calcium silicate/HAp nanocomposite has shown improved mechanical properties and bioactivity for HAp with the increase in calcium silicate concentration [10].

There are several reports claiming the enhancement of mechanical properties with the incorporation of forsterite but very few studies have been published to enhance the apatite deposition ability of forsterite bioceramic. Thus, the present work is an attempt to improve the reactivity of forsterite by fabricating its composites with bioactive wollastonite. Wollastonite and forsterite powders were synthesized by the sol-gel combustion method and mixed in different ratios. The properties of composites were compared based on their compositions. The fabricated composites were characterized using different characterization techniques, and the influence of the compositional ratio on the apatite formation ability was evaluated.

\section{Materials and method}

Sodium chloride (99.9\%, AR, SDFCL), sodium bicarbonate, Extrapure (99.5\%, AR, SRL), potassium chloride (99.5\%, AR, SDFCL), di-potassium hydrogen orthophosphate (99.0\%, AR, SDFCL), magnesium chloride (99.0\%, AR, SDFCL), hydrochloric acid (35-38\%, LR SDFCL), calcium chloride 
Table 1. Composition of wollastonite/forsterite composites.

\begin{tabular}{lccc}
\hline S. no & Code & $\begin{array}{c}\text { Composition of } \\
\text { wollastonite }\end{array}$ & $\begin{array}{c}\text { Composition of } \\
\text { forsterite }\end{array}$ \\
\hline 1 & CC1 & 80 & 20 \\
2 & CC2 & 70 & 30 \\
3 & CC3 & 50 & 50 \\
\hline
\end{tabular}

(98.0\%, AR, SDFCL), sodium sulphate anhydrous $(99.5 \%$, AR, SDFCL), Tris(hydroxymethyl)aminomethane (99.8\%, AR, SDFCL) and deionized water were used.

\subsection{Preparation of bioceramics}

The detailed procedure followed for the preparation of wollastonite and forsterite is described elsewhere [11,12]. Different ratios of pure wollastonite and forsterite were finely ground using an agate mortar and pestle. The composite was pelletized into a scaffold by a hydraulic pellet press (KBr press). The pressure applied for the preparation of the scaffold was $150 \mathrm{~kg} \mathrm{~cm}^{-2}$. The dimensions of the scaffold were $13 \mathrm{~mm}$ diameter and $2 \mathrm{~mm}$ thick. The ratios of wollastonite to forsterite were used to prepare composites and the details are shown in table 1.

\subsection{In vitro biomineralization assessment}

The apatite deposition ability of wollastonite/forsterite scaffolds was studied in simulated body fluid (SBF). The SBF was prepared as per the Kokubo and Takadama protocol. The scaffolds were immersed in $50 \mathrm{ml} \mathrm{SBF}$ in a sealed conical flask for 21 days. The samples were incubated without shaking at $37^{\circ} \mathrm{C}$ and the SBF medium was refreshed after every $24 \mathrm{~h}$. The scaffolds were collected from the solution in different intervals, washed gently with distilled water and dried at $60^{\circ} \mathrm{C}$ for $1 \mathrm{~h}$ using a hot air oven. The formation of HAp on the scaffold surface and variation in surface roughness were characterized by powder X-ray diffraction, Fourier-transform infrared, scanning electron microscopy and atomic force microscopy techniques.

\subsection{Characterization}

The depositions of HAp on the composites were examined by using a powder X-ray diffractometer (Model Bruker, D8 Advance) with $\mathrm{Cu} \mathrm{K} \alpha$ radiation. The functional groups in the composites were studied by using a Fourier transform infrared spectrometer (JASCO, 400). The morphology of the composite surface was characterized by using a scanning electron microscope (Carl Zeiss, EVO). The surface roughness before and after HAp deposition studies was analysed using an atomic force microscope (Nanosurf Easyscan 2). The ion concentration of $\mathrm{Ca}, \mathrm{P}, \mathrm{Mg}$ and $\mathrm{Si}$ in $\mathrm{SBF}$ was examined by inductively coupled plasma optical emission spectroscopy (ICP-OES, Perkin Elmer Optima 5300 DV).

\section{Results and discussion}

\subsection{Surface analysis of the composites before immersion in $S B F$}

The FT-IR spectra of the wollastonite/forsterite composites with different ratios (80:20 (CC1); 70:30 (CC2) and $50: 50(\mathrm{CC} 3))$ are shown in figure $1 \mathrm{a}-\mathrm{c}$. The absorption band at $475 \mathrm{~cm}^{-1}$ corresponds to $\mathrm{O}-\mathrm{Mg}-\mathrm{O}$ bending vibrations. Figure 1c shows that the CC3 sample exhibits a high-intensity peak at $475 \mathrm{~cm}^{-1}$ as compared with $\mathrm{CC} 1$ and $\mathrm{CC} 2$ samples. The peaks in the range of 518 to $620 \mathrm{~cm}^{-1}$ and 644 to $685 \mathrm{~cm}^{-1}$ are associated with bending vibrations of $\mathrm{O}$ $\mathrm{Si}-\mathrm{O}$ due to forsterite and wollastonite contents, respectively. The $\mathrm{Si}-\mathrm{O}$ symmetric stretching was observed at $842 \mathrm{~cm}^{-1}$. The broad band at $902 \mathrm{~cm}^{-1}$ was attributed to non-bridging $\mathrm{Si}-\mathrm{O}-\mathrm{Ca}$. The symmetric stretching vibrations of $\mathrm{Si}-\mathrm{O}-\mathrm{Si}$ were found at $1012 \mathrm{~cm}^{-1}$. These functional groups correspond to the presence of both wollastonite and forsterite in the composites $[11,12]$. The CC1 composite shows an irregular morphology with micro-pores, cracks and flake-like crystals on the surface (figure 1d). The CC2 composite (figure 1e) exhibits an irregular morphology while the CC3 composite (figure 1f) shows an uneven morphology.

\subsection{Surface roughness analysis}

The surface topography of the composite was examined by AFM. Figure 2 represents the 2D topographical view of wollastonite/forsterite composites. The surface of the CC1 composite (figure 2a) appears to have tiny circular particles distributed over the surface while the CC2 composite (figure 2c) shows bunches of particles distributed over the surface. In the case of $\mathrm{CC} 3$, the particles were found to possess different dimensions due to aggregation (figure 2e). The surface roughness of composites was found to be 206.94 (CC1), 180.89 (CC2) and $108.6 \mathrm{~nm}$ (CC3). Among all three composites, $\mathrm{CC} 1$ shows the maximum surface roughness.

\subsection{XRD analysis}

The XRD patterns (figure 3) of the wollastonite/forsterite composites after immersion in SBF indicate the formation of apatite on their surface. The surface of the CC1 composite was covered by HAp within 7 days of immersion. The apatite peaks exactly match with the JCPDS card no. 01-074-0566 associated with the HAp phase. The peaks appeared more prominently at $2 \theta=32.31,26.22,40.03,49.89$ and $53.50^{\circ}$ respectively corresponding to the $\left(\begin{array}{lll}2 & 1 & 1\end{array}\right),\left(\begin{array}{lll}0 & 0 & 2\end{array}\right),\left(\begin{array}{lll}3 & 1 & 0\end{array}\right)$, ( $\left.\begin{array}{lll}2 & 1 & 3\end{array}\right)$ and (l $\left.\begin{array}{lll}0 & 0 & 4\end{array}\right)$ planes of HAp. The wollastonite and forsterite peaks were not observed on the surface of the scaffold which confirms the complete coverage of the HAp layer 


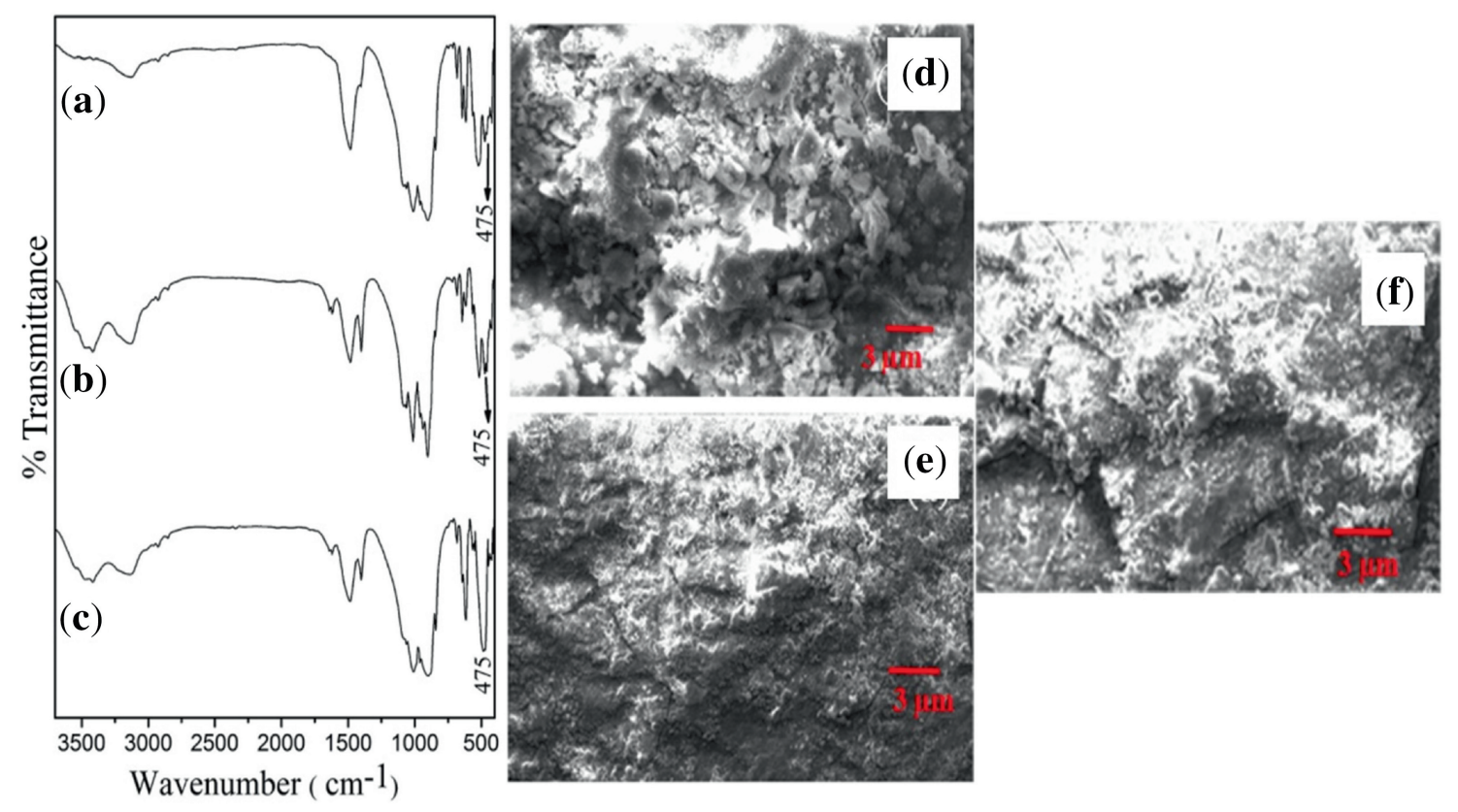

Figure 1. FT-IR spectra and SEM micrographs of $(\mathbf{a}, \mathbf{d}) \mathrm{CC} 1,(\mathbf{b}, \mathbf{e}) \mathrm{CC} 2$ and (c, f) CC3 composites.
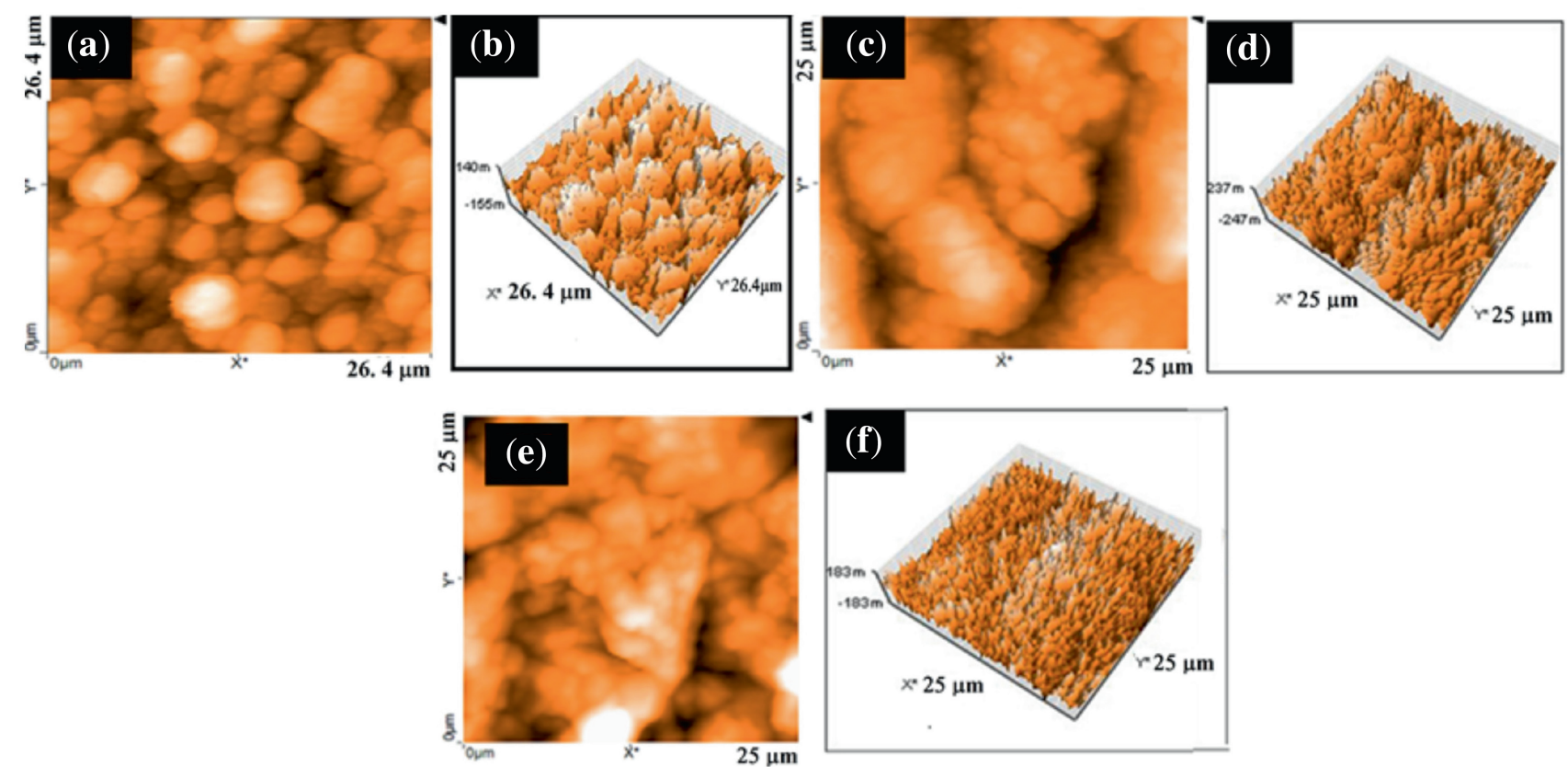

Figure 2. AFM images of composites $(\mathbf{a}, \mathbf{b}) \mathrm{CC} 1,(\mathbf{c}, \mathbf{d}) \mathrm{CC} 2$ and $(\mathbf{e}, \mathbf{f}) \mathrm{CC} 3$ before biomineralization studies.

on the surface of the $\mathrm{CC} 1$ composite. An increase in the intensity of the HAp peak was noticed as the immersion time was extended from 14 to 21 days.

A similar observation was detected in the XRD pattern of the $\mathrm{CC} 2$ composite showing the presence of apatite peaks within 7 days of immersion. It was also noticed that the surface of the CC2 composite comprises dual phases associated with forsterite and apatite. Hence, when the CC2 composite was further immersed in SBF for 21 days, a sharp increase in the intensity of HAp peaks was observed. This indicates that the consumption of necessary ions from the SBF facilitated the deposition of the $\mathrm{Ca}-\mathrm{P}$ layer covering the entire surface of the CC2 composite.

The CC3 composite shows slow apatite formation when compared with $\mathrm{CC} 1$ and $\mathrm{CC} 2$. After one week of immersion, the surface of the CC3 composite was composed of apatite 

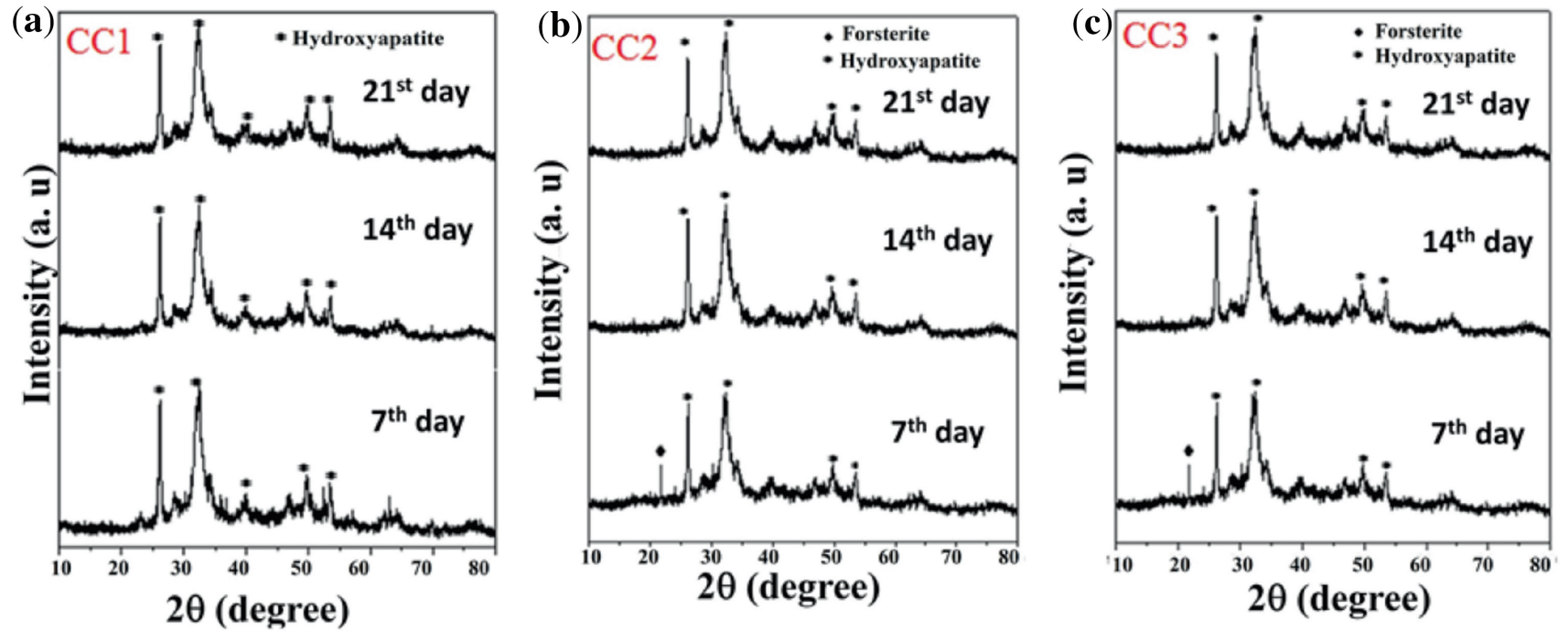

Figure 3. XRD pattern of composites (CC1, CC2 and CC3) after immersion in SBF.

phase accompanied by wollastonite and forsterite (figure 3 ). The influence of the immersion time (14 days) on apatite deposition indicates that the surface of the CC 3 composite was completely covered by the amorphous apatite layer. The deposited HAp matches with the standard JCPDS card no. 01-072-1243. It was also observed that with the increase in the immersion time ( 21 days) the intensity of HAp peaks enhanced. The literature suggests that forsterite has very less apatite formation ability while wollastonite has remarkable apatite formation ability over other silicate bioceramics [13]. Thus, the current work shows that the apatite deposition ability of forsterite can be improved by preparing its composites with wollastonite.

The variation in biomineralization activity on the surface of composites can be related to the change in their compositional ratio. From the above observation, it can be concluded that an increase in the wollastonite content enhanced the apatite deposition ability of the composites and viceversa. Therefore, the combination of bioactive wollastonite with the superior surface properties of forsterite resulted in remarkable bonelike apatite precipitation on the surface of composites.

\subsection{SEM/EDX analysis of the composites after immersion in $S B F$}

The surface morphology and elemental composition of wollastonite/forsterite composites after immersion in SBF were analysed. The surface of the CC1 composite was covered by small HAp particles. The deposited HAp was found to be highly homogeneous having a spheroidal-like morphology (figure 4a). The CC2 composite reveals the clusters of HAp particles on the surface (figure $4 \mathrm{c}$ ). The agglomerated spherical morphology was observed in the case of the CC3 composite (figure 4e). The variations in the surface morphology of composites were due to the difference in their apatite
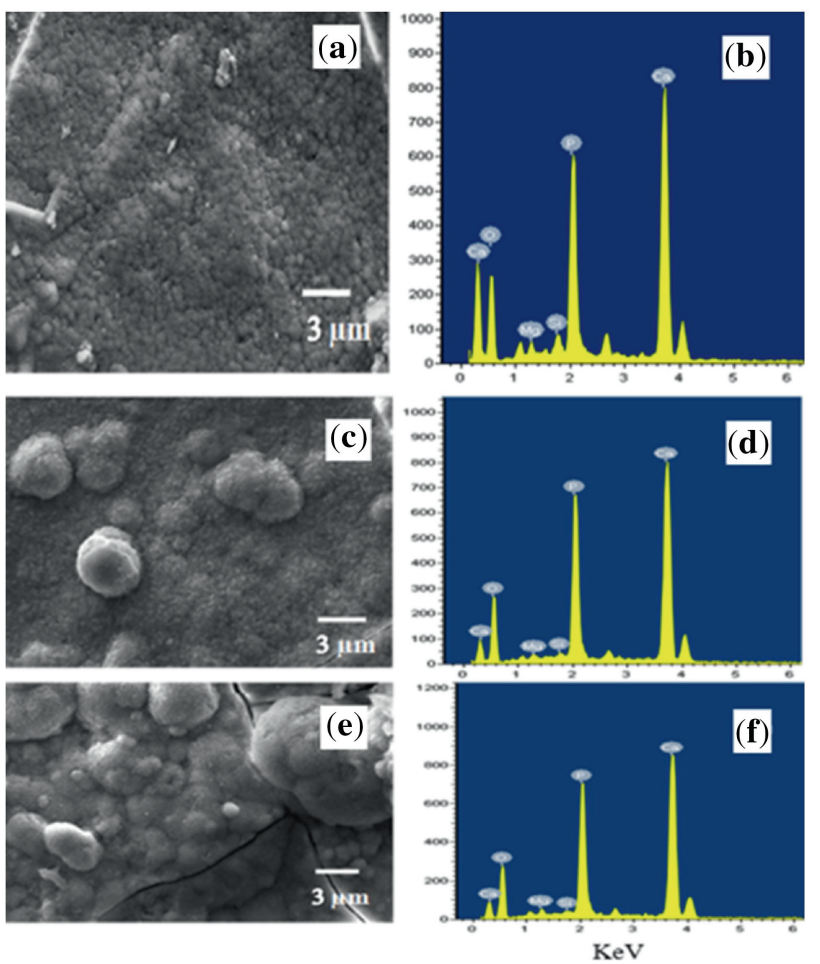

Figure 4. SEM and EDX patterns of $(\mathbf{a}, \mathbf{b}) \mathrm{CC} 1,(\mathbf{c}, \mathbf{d}) \mathrm{CC} 2$ and $(\mathbf{e}, \mathbf{f}) \mathrm{CC} 3$ composites after immersion in SBF.

deposition rate. The appearance of the phosphate peak in the EDX spectra of composites further confirms the apatite precipitation (figure $4 b, d$ and $f$ ).

\subsection{AFM analysis}

The surface of composites has shown a significant difference in their topography after HAp deposition (figure 5). The 


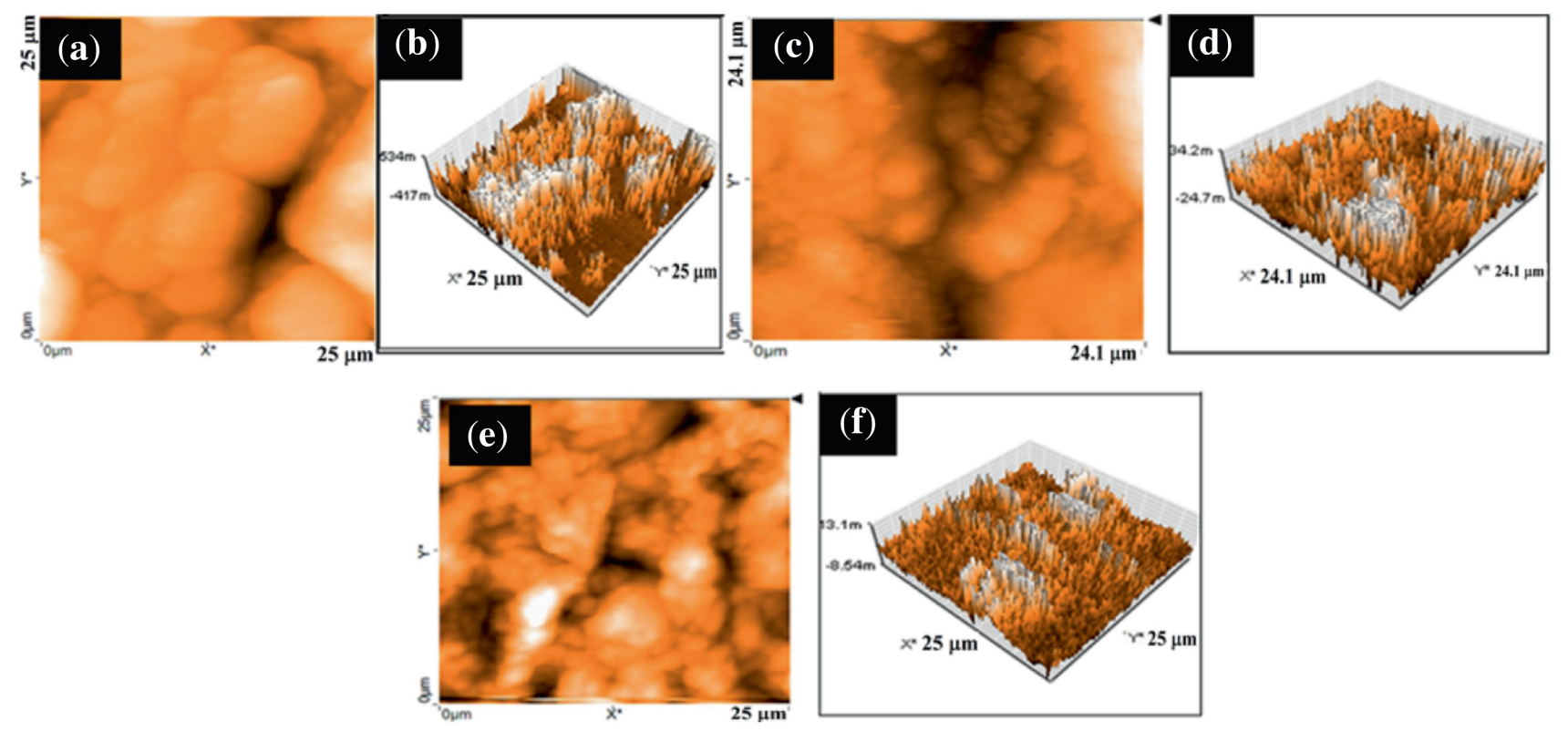

Figure 5. AFM images of (a, b) CC1, (c, d) CC2 and (e, f) CC3 composites after immersion in SBF.

Table 2. Surface roughness value of wollastonite/forsterite composites.

\begin{tabular}{lccc}
\hline S. no & $\begin{array}{c}\text { Wollastonite/forsterite } \\
\text { composite }\end{array}$ & $\begin{array}{c}\text { Before HAp } \\
\text { deposition, nm }\end{array}$ & $\begin{array}{c}\text { After HAp } \\
\text { deposition, nm }\end{array}$ \\
\hline 1 & CC1 & 206.9 & 2126.6 \\
2 & CC2 & 180.8 & 1906.5 \\
3 & CC3 & 108.6 & 1874.2 \\
\hline
\end{tabular}

increase in the size of the particles observed on the surface of the CC1 composite was due to a faster growth of apatite particles (figure 5a). This led to the increase in the surface roughness of the composite. A similar pattern was noticed for CC2 and CC3 composites as well. The surface roughness values of composites after apatite deposition are tabulated in table 2. The major reason for such variations in their surface roughness values was due to the rate at which apatite deposition took place. The faster the apatite deposition, the higher the roughness noticed. These results indicate that the deposition rate also affects the surface properties of the materials.

\subsection{Dissolution analysis}

The variations in the activity of wollastonite/forsterite composites were further studied by their dissolution behaviour in SBF. It has been suggested that the dissolution analysis plays a major role in predicting the biological response of materials in the physiological environment $[14,15]$. ICP-OES analysis was carried out to examine the concentration of $\mathrm{Ca}, \mathrm{Si}, \mathrm{P}$ and $\mathrm{Mg}$ ions released/consumed during apatite deposition by the wollastonite/forsterite composites. The ion release kinetics of the $\mathrm{CC} 1$ composite (figure 6a) shows a drastic change in $\mathrm{Ca}$ and $\mathrm{P}$ ions from 103 to $74 \mathrm{ppm}$ and 42 to $23 \mathrm{ppm}$ while an increase in the concentration of $\mathrm{Mg}$ ions was found (from 30 to $47 \mathrm{ppm}$ ). The calcium and phosphorus ions are considered as necessary ions responsible for apatite deposition. Hence, the continuous consumption of calcium and phosphorus ions decreased their concentration in the SBF. Magnesium is not required for apatite formation, as a result, an increase in its concentration was detected throughout the immersion period. In addition, Si ions were negligibly leached out from the composites.

A uniform reduction in the concentration of $\mathrm{Ca}$ and $\mathrm{P}$ ions was observed till the end of biomineralization studies (figure 6b). The calcium concentration decreased from 99 to $75 \mathrm{ppm}$ while 40 to $20 \mathrm{ppm}$ was detected in the case of phosphorus. This dissolution response was found comparably similar to the $\mathrm{CC} 1$ composite and confirms the precipitation of HAp on the surface of the CC2 composite. The release profile of the magnesium ion in the SBF was found to increase constantly (27-45 ppm) showing its negligible utilization in apatite deposition. Moreover, no significant change in the $\mathrm{Si}$ level was observed in the SBF.

Figure $6 \mathrm{c}$ shows a distinct dissolution profile of the CC3 composite in the SBF. The poor consumption of calcium and phosphorus ions from the medium resulted in slow apatite formation activity of the $\mathrm{CC} 3$ composite. The reason for the sudden change in the activity was due to the higher compositional ratio of forsterite in the CC3 composite when compared with other composites and thus the SBF was enriched in magnesium ions. Previous findings state that magnesium retards the apatite deposition ability of a bioceramic. 

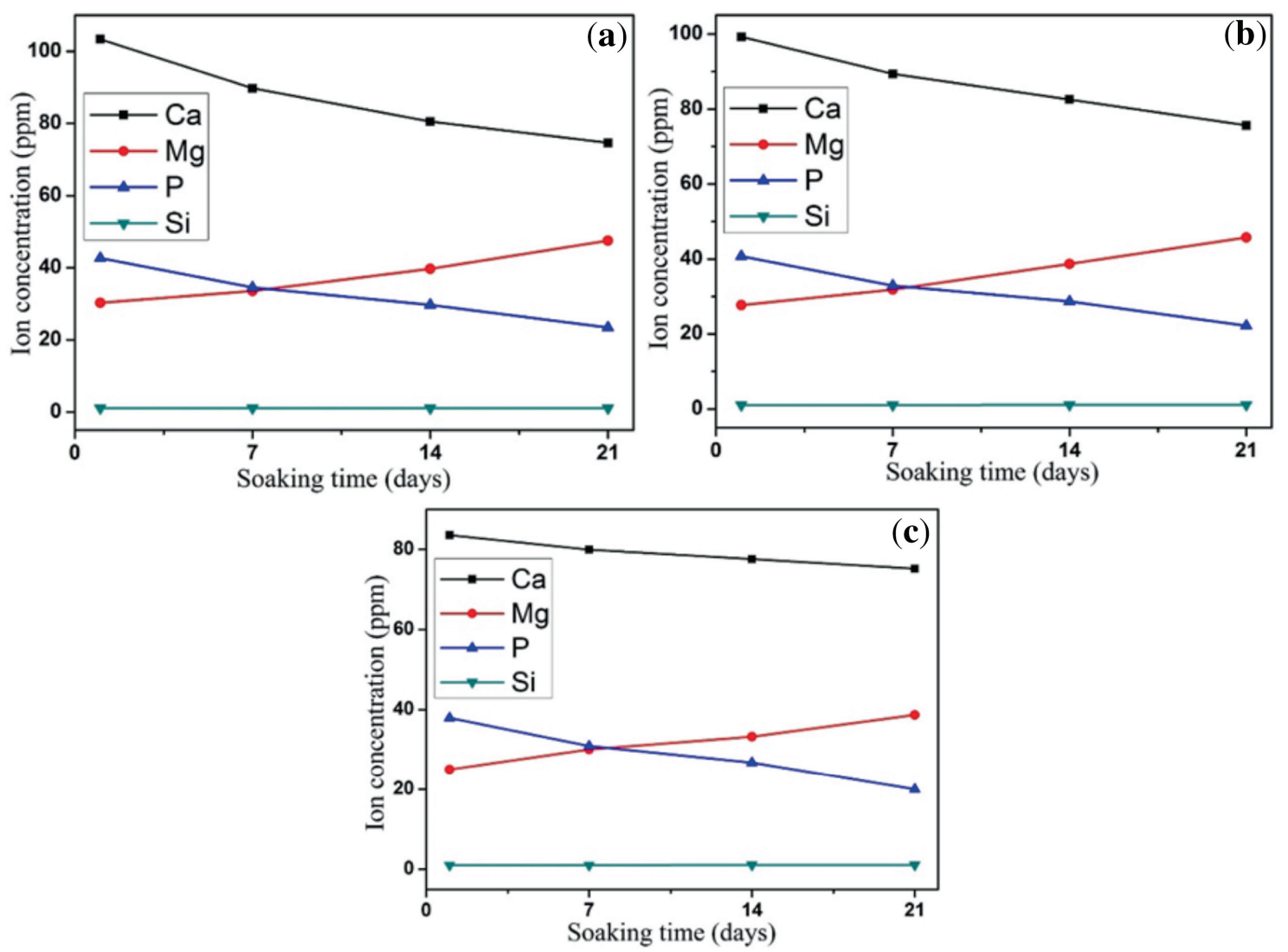

Figure 6. Ionic concentration of (a) $\mathrm{CC} 1$, (b) $\mathrm{CC} 2$ and (c) $\mathrm{CC} 3$ composites during immersion in SBF.

The magnesium ion delays the crystallization rate of the amorphous $\mathrm{Ca}-\mathrm{P}$ film and suppresses the conversion of amorphous $\mathrm{CaO}-\mathrm{P}_{2} \mathrm{O}_{5}$ into stable apatite [16]. The literature states that the $\beta$-wollastonite/forsterite composites containing 50 and $70 \%$ calcium silicate were more suitable candidates for bone repairing application [7]. But current work suggests that $80 \%$ wollastonite content can also be a desirable composite. In order to confirm this notion, a detailed cellular investigation of these composites is required. These results show that chemical composition also plays a vital role in determining the apatite deposition ability of bioceramics.

The dissolution analysis confirmed that the $\mathrm{CC} 1$ composite exhibited good HAp deposition ability compared to other composites. This was found in concordance with the XRD analysis of the composite surface after immersion (figure 3). As the compositional ratio of forsterite in composites was increased the apatite deposition ability affected. The presence of wollastonite in composites was found to exert more influence on in-vitro biomineralization. Hence, the incorporation of forsterite nanopowders in the bioactive wollastonite matrix has influenced the apatite formation ability of the wollastonite/forsterite composite.

The wollastonite/forsterite composites undergo several interfacial reactions during immersion in SBF. The detailed mechanism of these reactions is explained as follows. When the composites are immersed in SBF, an ion exchange step is initiated. This process causes the exchange of alkali earth ions $\left(\mathrm{Ca}^{2+}\right.$ and $\left.\mathrm{Mg}^{2+}\right)$ from the composites with hydrogen ions present in the SBF. This leads to the breakdown of the silica network into silanol at the interface of the composites. The silanol further undergoes a polycondensation reaction with hydroxyl ions $\left(\mathrm{OH}^{-}\right)$from the SBF to form a silica-rich layer $\left(\mathrm{Si}-\mathrm{O}^{-}\right)$with the elimination of water. Studies reveal that the silica-rich layer provides necessary sites to induce apatite nucleation [17]. Therefore, an increase in silica linkages on the surface might provide the possibility of forming more amounts of the silica-rich layer. The silica groups present in the composites are found to be more when compared with wollastonite $\left(\mathrm{CaO} \cdot \mathrm{SiO}_{2}\right)$ or forsterite $\left(2 \mathrm{MgO} \cdot \mathrm{SiO}_{2}\right)$ alone. The negatively charged silica-rich layer attracts cations $\left(\mathrm{Ca}^{2+}\right)$ from the SBF and later anions $\left(\mathrm{PO}_{4}^{2-}\right)$ to initiate $\mathrm{Ca}-\mathrm{P}$ formation at the interface. The concentration of calcium and phosphorus ions in the SBF can be correlated with the dissolution studies showing a constant decrease after 7 days (figure 6). This process continues, leading to deposit an amorphous $\mathrm{CaO}-\mathrm{P}_{2} \mathrm{O}_{5}$ film. Later, carbonate and hydroxyl anions crystallize the film into calcium deficient hydroxycarbonate apatite [18]. This indicates that the silicon content also plays a vital role in apatite deposition on the surface of silicate bioceramics [19]. Therefore, the chemical constituents, 
compositional ratio and dissolution rate were found to play a vital role in examining the biomineralization ability of wollastonite/forsterite composites.

\section{Conclusion}

In this study, different ratios of wollastonite/forsterite bioceramic composites were fabricated. In-vitro biomineralization studies reveal the formation of the HAp layer on the surface of wollastonite/forsterite composites. It was also found that the CC1 composite shows higher HAp deposition ability when compared to $\mathrm{CC} 2$ and $\mathrm{CC} 3$ composites, as it contains more amounts of wollastonite. SEM studies disclose the irregular morphology of wollastonite/forsterite composites before in-vitro studies. After apatite deposition, the agglomerated spherical morphology was observed for the composite. We demonstrated that the composites containing $80 \%$ wollastonite content increase the surface roughness and enhance the apatite formation ability of forsterite.

\section{Acknowledgements}

The authors thank DST-FIST for the XRD, SEM facility and SAIF/IIT Madras for ICP-OES facility. This study was financially supported by Vellore Institute of Technology Research Grants for Engineering, Management and Science (VITRGEMS).

\section{References}

[1] Deng J, Li P, Gao C, Feng P, Shuai C and Peng S 2014 Mater. Manuf. Process. 29877
[2] Sopyan I, Gunawan Shah Q H and Mel M 2016 Manuf. Process. 31713

[3] Ilyuschenko A, Okovity V A, Shevtsov A I, Kashin N G and Kulak A I 2002 Mater. Manuf. Process. 17 177

[4] Sopyan I, Nawawi N A, Shah Q H, Ramesh S, Tan C Y and Hamdi M 2011 Mater. Manuf. Process. 26908

[5] Kharaziha M and Fathi M H 2009 Ceram. Int. 35 2449

[6] Ni S and Chang J 2009 J. Biomater. Appl. 24139

[7] Ni S, Chou L and Chang J 2008 J. Mater. Sci. Mater. Med. 19 359

[8] Dinarvand P, Seyedjafari E, Shafiee A, Jandaghi A B, Doostmohammadi A, Fathi M Het al 2011 ACS Appl. Mater. Interfaces 3 4518

[9] Sebdani M M and Fathi M H 2012 Ceram. Int. 38 1325

[10] Beheri H H, Mohamed K R and El-Bassyouni G T 2013 Mater. Des. 44461

[11] Lakshmi R and Sasikumar S 2012 Adv. Mater. Res. 584 479

[12] Choudhary R, Manohar P, Vecstaudza J, Yáñez-Gascón M J, Pérez Sánchez H, Nachimuthu R et al 2017 Mater. Sci. Eng. C 77811

[13] Lin K L, Zhai W Y, Chang J, Zeng Y and Qian W J 2005 Ceram. Int. $\mathbf{3 1} 323$

[14] García-Páez I H, Pena P, Baudin C, Rodríguez M A, Cordoba E and De Aza A H 2016 Bol. Soc. Esp. Ceram. V. 551

[15] Choudhary R, Vecstaudza J, Krishnamurithy G, Balaji Raghavendran H R, Murali M R, Kamarul T et al 2016 Mater. Sci. Eng. C 6889

[16] Vallet-Regi M, Salinas A J, Roman J and Gil M 1999 J. Mater. Chem. 9515

[17] Liu X, Ding C and Chu P K 2004 Biomaterials 25 1755

[18] Kim H M, Himeno T, Kokubo T and Nakamura T 2005 Biomaterials 264366

[19] Hou X, Yin G, Chen X, Liao X, Yao Y and Huang Z 2011 Appl. Surf. Sci. 2573417 